\title{
The Mechanism of Nuclear Division.
}

BY

W. LAWRENCE BALLS, M.A.

Fellow of St. John's College, Cambridge; Botanist to the Khedivial Agricultural Society, Cairo; Membre de l'Institut Egyptien.

With Plate LIV and one Figure in the Text.

INTRODUCTION. ${ }^{1}$

$\mathrm{M}$ ORE attention has been given by cytologists to the chromatic substances of the nucleus than to the achromatic substances, partly on account of the difficulty of observing the latter.

Attention has been further attracted to the chromosomes by the discovery of numerical constancy, by their localization as the germ-plasm, and lately by Mendelian developments. The study of the achromatic structures has lagged behind, and our knowledge of their behaviour in the process of karyokinesis is consequently incomplete.

We have no good evidence as to the way in which the spindle fibres are formed, nor of the changes which take place between the splitting of the spireme and their appearance. Many hypotheses have been advanced concerning the spindle fibres, but none of them hold out any hope of generalization. Botanical studies on these structures received a check by the disproof of Guignard's work on the centrosome, and the artifact preparations obtained by other workers have made the cytologist very chary of publication.

1 Since this paper will presumably be read by professed cytologists, to whose ranks the writer cannot claim to belong, a word regarding the circumstances of its publication seems advisable, by way of apology. The observations arose during an examination of the sexual cytology of Egyptian cotton, made in 1905 as a preliminary to Mendelian research on this plant. They were continued for a year, and the present paper, in its present form, was written during the summer of igo6. The conclusions seemed so heterodox that publication was delayed till more evidence could be accumulated from other plants, such as Hibiscus spp., which might be expected to show similar phenomena to those exhibited by Gossypium. Pressure of other work in Genetics and Physiology has prevented the acquisition of such supplementary evidence, and this four-year-old account is now being published in the hope that other botanists, better qualified than the writer, may find something of use in its pages, even if the generalization here advanced may not hold good.

The substance of this paper was communicated to the Cairo Scientific Society early in I 9o6, and an abstract was read and published at the Dublin meeting of the British Association in 1908.

[Annals of Botany, Vo1. XXIV. No. XCVI. October, IgIo.] 
The large amount of 'achromatin' in the nuclei of the cotton-plant has enabled me to study there some processes which are not readily seen elsewhere. The interpretations which I have placed upon these observations appear to correlate several parts of the problem of the achromatic structures, but the work needs to be tested by other observers.

If the results about to be described are confirmed, it will probably be found that the principle of the matter holds good for the whole organic world.

\section{Historical Summary. ${ }^{1}$}

Bütschli, Van Beneden, and Strasburger (in his early researches) believed that the whole mitotic figure was formed from nuclear substance. Fol also considered that the spindle was derived from the nucleus, but regarded the asters as of cytoplasmic origin.

Strasburger changed his opinion at a later period and formulated the conceptions of 'kinoplasm' and 'trophoplasm'. Both of these were cytoplasm in origin; the former being seen as threads which invade the nucleus when the nuclear wall disappears, and acting as the motor mechanism in cell-division.

\section{The Spindle Fibres.}

The mode of origin of the spindle fibres has been explained in almost every conceivable way by those who hold them to be tangible structures. Further confusion is introduced by those who do not see their way to accepting them as real, but regard them as manifestations of some physical stress in the protoplasm.

The popular comparison of the spindle to a field of force between two opposite magnetic poles is only persuasive when the observed organism develops centrosomes and asters. We can conceive of the centrosome as a storm-centre of metabolism which radiates lines of metabolic disturbance, although the centrosome is a very minute organ; but when the astral rays are missing, and the single centre has broken up into a score, or more, must we not then assume that the single line from the inner side of each of these is the sole manifestation of this intense metabolic change? There seems to be no reason why this change should be confined to one side of a granule which is smaller than the wave length of sodium light.

Even if we grant the existence of these lines of metabolic stress, we still lack an explanation of the way in which the chromosome is moved.

Strasburger's suggestion that the chromosomes are chemotactically sensible seems rather unlikely. The chromosomes would have to be selfmotile. Now, the chromosome is so closely concerned with the transmission of heritable characters-a function of fundamental importance-that

1 For references see E. B. Wilson, The Cell in Development and Inheritance. 
during its phylogeny it has probably lost all other powers and become a passive organ, handed about by other organs which are the blind agents for the distribution of the controlling substance, although they themselves are incapable of directing the fortunes of the cell.

Some such unprejudiced mechanism is required to explain the Mendelian facts of gametic distribution, and the achromatic structures seem to be this mechanism.

The only satisfactory explanation seems to be given by admitting the reality of the spindle fibres, and by assuming the power of contractility in the achromatic structures generally. There is no assumption of vitalism in the latter step, for the fact of fibrillar contractility is fully acknowledged in pseudopodia and cilia. There is, moreover, a probability that future physical research upon surface tension in thin films and threads may be able to give us a physical explanation of the phenomenon. Contractility in the spindle fibres was first advocated by Klein and Van Beneden; Boveri demonstrated that the fibres became shorter and thicker; Hermann showed that the central spindle fibres elongated in mitosis. Hertwig and Wilson were unable to see any increase in the thickness of the fibres, but it must be remembered that these fibres are so delicate that one may be unable to distinguish the diffraction image of a thin one from the real image of a thicker one.

Strasburger has cleared the way for a conception of motor mechanism in cell-division, or 'kinoplasm', but he does not differentiate between the nuclear and cytoplasmic portions, whereas I have reason to consider the two forms as morphologically distinct, though perhaps chemically similar or identical.

\section{The Centrosome.}

A persistent nucleolo-centrosome which divides to form a spindle is found in some unicellular organisms. This body is considered as equivalent to the centrosome. The 'end-plates' of Actinosphaerium arise by the division of a nucleolus or plasmosome, and it would seem from the general evidence of these primitive organisms that the achromatic plasmosome and the centrosome have a genetic relationship. This is even more distinct in the case of Paramoeba, whose 'Nebenkörper' consist of extruded achromatic substance. From this we pass to Hertwig's work on Actinosphaerium, where the centrosomes are proved to arise from the reticulum which is extruded at the poles, and this agrees with the increasing number of cases recorded in which the centrosomes are formed anew.

When asters are found in organic cells they generally seem to be of cytoplasmic origin, and independent of the centrosome. The observations recorded below have led me to the opinion that the asters are heterogeneous, the outer portion being merely stream-lines in the cytoplasm, while the remainder of the rays are true fibres, derived from the achromatic nuclear 
structures and connected with the modified portion of those structures which is called the centrosome.

In the higher plants the centrosome is again absent, and the scheme of division (as interpreted below) is similar to that of the Infusoria. We may hope that the results to be obtained by study of the fate of the achromatic structures in higher plants will ultimately be translated into terms of the specialized centrosome of the lower plants and the animals.

\section{Cell-Division in CotTon.}

While studying the cytology of the flower of Egyptian cotton ${ }^{1}$ during the summer of I905, I noted certain novel and curious structures in cells which were undergoing the reduction division.

The staminal column turns yellow when the flower bud is still young, the anthers having previously been of a pale buff colour. Material taken about two days before this change of colour shows the microspore mothercells in all stages of development, from synapsis to walled spores, in a single flower.

The synaptic stage (Fig. 2, Pl. LIV) is of the usual kind. The nucleus is comparatively small-about twenty microns in diameter-and contains a large plasmosome, which stains darkly with Heidenhain's haemotoxylin. A lightly stained, densely tangled, coiled thread is connected to this nucleolus. The spireme thread appears to be continuous. The spireme thread then begins to open out, and becomes a looser tangle (Fig. 3). In it are embedded rows of darkly-staining granules, each one showing a distinct longitudinal bisection.

The nucleolus next decreases in size, and the granules stain more darkly; the shrinking of the nucleolus appears to be very rapid, for the stage is rare; the darkening of the granules is localized to those portions of the thread which correspond to the future position of the chromosomes. Except in these portions the thread of the spireme is now split.

Each of these clusters of darkened granules becomes a mass of chromatin, or bivalent chromosome. This chromosome is not, however, merely bisected as were the granules, but is also divided transversely to the axis of the spireme thread; four perfectly distinct chromatic areas are thus formed, being the four univalent chromosomes which are to be distributed to the four microspores. These quarters, or daughter chromosomes, are roughly spherical, not elongated. By this time (Fig. 4) the nucleolus is no wider than the spireme thread, with which it is seen to be continuous on both sides, and it scarcely stains at all with haemotoxylin. All trace of it is lost shortly afterwards.

1 Balls, W. Lawrence: The Sexuality of Cotton. Khed. Agric. Soc. Yr. Bk., 1905. For systematic position of the variety studied (Afifi) see Sir G. Watt's Wild and Cultivated Cottons. 
The mode of formation of these chromosomes rather suggests a transference of chromatin from the nucleolus to the chromosome areas by progressive chemical change in the original paired granules.

The chromosomes are bunched together at one side of the nucleus. There is no regular peripheral distribution. In this respect cotton differs from most organisms, and from its own vegetative cells. These chromosomes are minute, being only 0.6 micron in diameter, while the univalent chromosomes are correspondingly smaller still. In consequence of this fact the achromatic substance of the nucleus is quite conspicuous, in spite of its slight stain affinity.

The nucleus of the microspore mother-cell thus consists at this stage of twenty chromosomes grouped to one side, and these chromosomes lie in a continuous split spireme thread which is composed of achromatic substance. The nuclear wall has faded away, and the periphery of the nucleus is occupied by a densely granular zone of cytoplasm, which has been visible outside the wall for some time.

The next stage is the most important one, and also the most difficult one to observe. It is completed rapidly-to judge by its comparative rarity - and the achromatic structures form a most complex tangle. The sequence of events appears to be as follows:-The two halves of the split spireme thread move apart from one another at the side where the chromosomes are lying, but this separation does not affect the chromosomes. The chromosomes are isolated by the removal of the spireme halves, but not entirely, for continuity with the latter is maintained by thin filaments on either side (Fig. 5). The insertion of these filaments (the young spindle fibres) in the spireme halves causes slight swellings which appear to the eye as black dots.

From this point I propose to refer to the spireme halves as the 'threadrings', retaining the term 'fibre' for its usual subject.

The two thread-rings continue to separate, the fibres becoming longer and longer, until the part of each thread-ring which bears the dots has moved to a pole of the nucleus. The dots are scattered round some $100^{\circ}$ of arc, and the remainder of each thread-ring forms an irregular tangle of loops, which lies between the centrally suspended chromosomes and the granular cytoplasm (Fig. 6). The looping of thread-rings seems to be due to the fact that the circumference of the close spireme is greater than the circumference of the nucleus. This stage constitutes the multipolar spindle.

The next event is the contraction of the dotted portions of the threadrings, bringing the dots nearer together, and forming the bipolar spindle of metaphase (Fig. 7). The looped thread-rings lying in the clear zone between spindle and granular cytoplasm are quite conspicuous; this was the observation which initiated the present research. It sometimes happens that a stray dot is not drawn up into the cluster at the pole as soon as it 
should have been; in this case the spindle fibre which ends in it remains at the side of the spindle, often slack and bent (Fig. 8) instead of being drawn taut.

The polar dots at the ends of the fibres have been noticed by other observers, but I can find no mention of their cross-connexion by the threads.

When separation of the chromosomes takes place in anaphase, the halves retain their continuity by means of fibres; these inter-chromosome fibres appear to be drawn out from the achromatic matrix of the chromosome. The original fibres between chromosome and dot become shorter without any noticeable thickening.

In telophase of this first division the cytoplasm invades the space between the two daughter nuclei, and the inter-chromosome fibres seem to be dissolved in it. There is, however, no disintegration of the thread-rings themselves; it seems quite plain, from the position of their loops in late telophase, and in early prophase of the second division (Fig. 9), that each of the two rings retracts into the daughter nucleus at its own pole, viz. at the pole where it is attached to spindle fibres. In this way the continuity of the thread-ring is never broken; the chromosomes are retracted into it, and it proceeds to divide again.

The second division follows the first without any noticeable delay. It is even less easy to observe, the spindle being smaller and barrel-shaped and leaving hardly any clear zone, but the threads are again visible, and the fibres terminate on them in dots as before.

The thread-ring divides longitudinally again. This division is visible in the earliest second division prophase (Fig. 10). Indeed, there is some probability (though this is not certain, on account of the complex looping) that it is visible in metaphase of the first division, or even earlier; when the two spireme halves are separating in first prophase there is occasionally a slight indication of a second division of each half. This would produce a fourfold spireme thread, in places, from the very beginning of the reduction division; it should be noted that this quartering is not effected in the same way as the quartering of the bivalent chromosome. The superposition of the loops of the threads in early prophase of the second division is very marked.

The mode of isolation of the chromosomes from the rings has not been clearly seen in second division. If the splitting of the rings precedes this division, then each chromosome is drawn up to the pole by at least two fibres, and the rings have simply to separate. Otherwise, the chromosome is presumably retracted into the ring, and the process of splitting repeated as in the first division.

In the beginning of the process of reconstitution of the four microspore nuclei it can be seen that the chromosomes are connected by threads and fibres, with the 'black dots' at the junction of these latter. It would 
seem that the black dots enlarge later, becoming the nodes of the reticulum in some cases. The wall of the nucleus seems to be entirely cytoplasmic in origin. Those spindle fibres which are divided by the wall fade away centripetally up to the wall, while the portion of each fibre inside persists, for a time at least, ending blindly in the wall at one end, and still connected at the other end with the chromosome from which it was formed.

The method of formation of those spindle fibres which run from pole to pole without bearing chromosomes has not yet been mentioned. They do not appear to be common in the nuclei of the cotton-plant; their mode of formation is the same as that of the other fibres, except that they are drawn out from the separating thread-rings at points other than those where the chromosomes are found.

The nuclei of the vegetative cells of the cotton-plant are very minute. ${ }^{1}$ A few observations have been made on them, using the root-tip of seedlings, but the ordinary vegetative cells of the flower tissues are far too small for study.

The scheme of division outlined above seems to apply to these cells also, with structural modifications due to the smaller circumference of the spireme relatively to the nucleus. The spireme has about the same diameter as the nucleus itself, and the achromatic threads are thicker; there are, consequently, no tangled loops to confuse the observer, but the larger number of chromosomes compensates for this. The chromosomes are not grouped to one side, but are symmetrically distributed in prophase around the periphery of the nucleus (Fig. II). The two spireme halves separate directly in parallel planes, instead of rotating over one another as in the reduction division, being evenly tied together by the spindle fibres. The spindle thus produced (Fig. I2) is very fat and broad, while the rings at each end are frequently quite conspicuous. The actual separation of the spireme halves, and the isolation of the chromosomes, is thus more easily recognized (Fig. II) than it is in the reduction division, although the nucleus is smaller. At the same time, the absence of loose loops of the thread-rings prevents the appearance of any striking structures. The 'dots' are often very distinct, and sometimes of appreciable size, being almost fit for description as plasmosomes.

The large plasmosome, or nucleolus, may either disappear or persist. In the latter case it may present appearances which suggest Wager's figures of the nucleolus in Phaseolus, ${ }^{2}$ excepting that his figures do not show the plasmosome to be in connexion with the thread-rings by means of thin filaments. These filaments give it the slightly stellate (Fig. II) appearance. About equally common is another arrangement (Fig. I3), in which the plasmosome is merely a local dilatation of the thread-ring. 


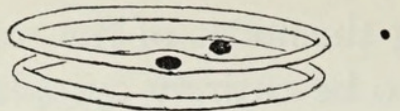

1.
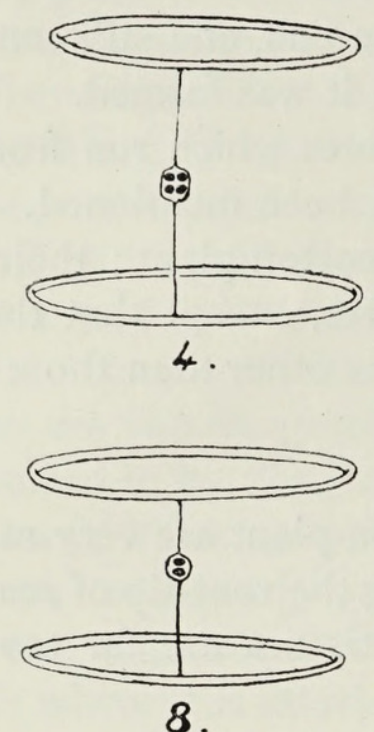

8.

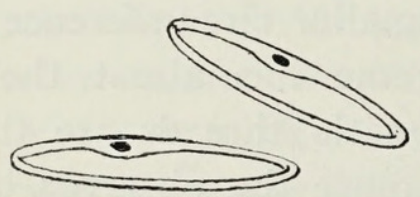

11.

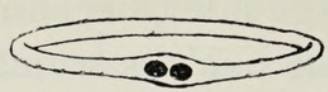

2.
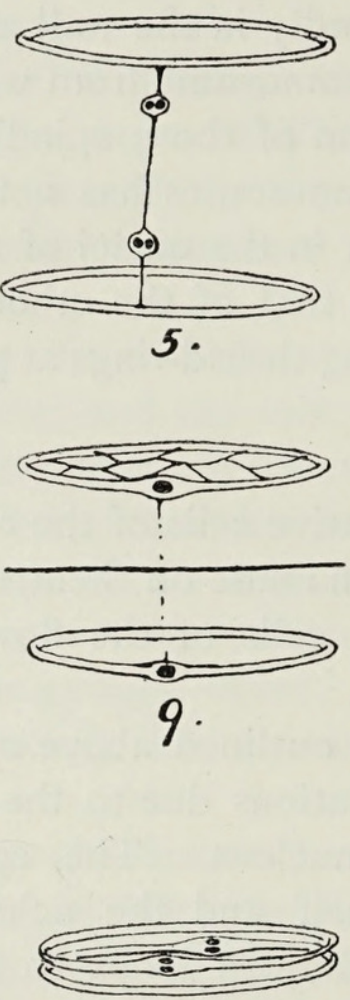

12

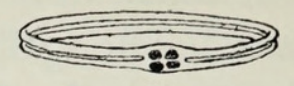

3.
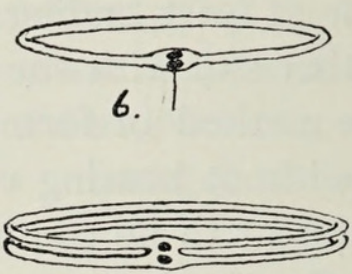

7.

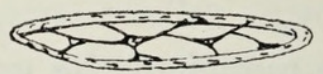

10.

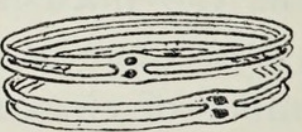

13.
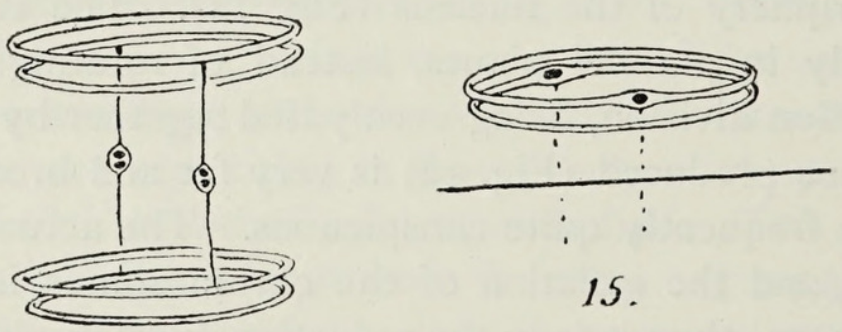

15.

14.

Diagram of the Nuclear Mechanism.

Diagrams made on the assumption that the fusion of the gamete nuclei is delayed until synapsis. If this fusion takes place at fertilization we have a simpler scheme. Fig. I then resembles Fig. 2, except in the chromosomes, and Figs. I2-I 5 are simpler.

r. Somatic nucleus with two chromosomes, each in its own thread-ring: i.e. one chromosome and ring from each gamete.

2. Synapsis; fusion of the rings, bivalent chromosomes.

First reduction division:-3. Prophase ; 4. Metaphase; 5. Anaphase; and 6. Telophase.

Second reduction division :-7. Prophase; 8 . Metaphase ; and 9. Telophase, with one represented as having cross-bridles.

Iо. Gamete nucleus; chromatic substance distributed through thread-ring and bridles.

II. Gamete nuclei approaching in fertilization.

1 2. First division of zygote : chromosomes dividing.

.

$\left.\begin{array}{lll},, & \text { ", } & \begin{array}{l}\text { prophase } \\ \text { metaphase } \\ \text {,elophase }\end{array}\end{array}\right\}$ Any somatic division.


The nucleolus is thus a mere swelling in the achromatic structures, whether in dividing or resting nuclei.

\section{Discussion of Observations ON COTTON.}

The two criticisms to which all cytological work has to submit relate to the pre-existence of observed structures in the living cell, and to the accuracy of the observations made upon those structures.

In respect to the first point we have the following facts in support of the reality of the thread-rings. The rings were seen ${ }^{1}$ in metaphase from material which had been very badly fixed with acetic-absolute. The majority of the observations were made on material fixed with chromacetic, or with strong Flemming ; the fixative was injected by an air-pump, transference through alcohols, xylols, and paraffin by twelve-hour stages took ten days, and after sections of five to eight microns thick had been cut, they were stained with Heidenhain's haematoxylin. In such material the fixation was excellent, even the cytoplasm being but little distorted. ${ }^{2}$ The appearances were consistent, and similar at each stage, differing only in such details as the number and position of the loops of the thread-rings. The loops are far more conspicuous-individually-than the spindle fibres, and if the reality of the latter is granted, that of the loops and black dots must also be conceded.

The 'artifact criticism' is of the greatest value in exercising a sceptical control over generalization upon insufficient evidence. Nevertheless, when, as in this case, an elaborate structure is developed stage by stage with the development of the cell which contains it, when the same structures can be recognized at every stage, and when nothing inconsistent with expectation makes its appearance, then the burden of proof rests on the artifact critic.

The fact that these structures have not before been found in other plants is only partially negative evidence against them; the dots at the ends of the spindle fibres have been seen by other observers. It must be borne in mind that the twenty chromosomes of cotton are extremely minute, that the nucleus is merely small, and that there is a large proportion of achromatic substance in comparison with the amount of chromatic substance.

The writer is less optimistic with regard to the accuracy of the observations. Still, he believes that subsequent corrections will only affect details, most of which have been indicated above. The absence of proper cytological refinements, microphotographic apparatus, and especially of a mercury vapour lamp, have all been against great accuracy of vision.

The Zeiss IV a stand was used, with Abbe condenser. The lens first employed was only the $\frac{1}{12}$-inch achromatic oil immersion; the main facts were ascertained with this. Subsequently the Khedivial Agricultural

1 See also note on Cannon's observations at the end of this paper.

2 See Figs, I and 2. 
Society very kindly procured me the Zeiss $3 \mathrm{~mm}$., I.40 num. ap., hom. imm., apochromatic objective; the rest of the work was done entirely with this. The eyepieces used were Nos. 2 and 4, with the Zeiss compensating oculars $\mathrm{I} 2$ and $\mathrm{I} 8$, on a tube of $\mathrm{I} 60 \mathrm{~mm}$.; most of the observations were effected with the 12 , using the 18 to differentiate in depth.

Lighting had to be considered very carefully, for the univalent chromosomes are little larger than the wave length of sodium light. It was therefore necessary to reduce the wave length of the light employed. In this respect the use of haemotoxylin had a great advantage, as it stains from black to grey. A water tank filled with a strong filtered solution of copper oxide in ammonia was placed before the Welsbach incandescent lamp, and its concentration was adjusted by the spectroscope until no light passed through below the $\mathrm{D}$ line. The full aperture of the condenser was used.

When the Welsbach lamp was in use, an image of the crossing of two wires of the mantle was focused upon the object. Later on, critical illumination was obtained by using a flat-wicked oil lamp.

Microphotographs were made of all the important stages. This method had its limitations, on account of the roughness of the apparatus, but it gave evidence in support of the eye.

The precise position assumed by the bivalent chromosome at the splitting of the spireme, and the number of spindle fibres formed for each chromosome, could not be ascertained by the methods I employed.

\section{Conclusions.}

The nucleus is an independent portion of the cell, morphologically discontinuous from the cytoplasm, and consisting solely of chromatin and achromatic substances.

The nuclear sap and membrane belong to the cytoplasm, serving to conduct the chemical interchange between nucleus and cytoplasm.

Assuming that our arbitrary mode of recognition of chromatin and achromatin is approximately just, it would seem that their respective functions might be somewhat as follows :-

\section{Chromatin.}

A mixture of complex bodies, probably the bearers of the hereditary qualities, incapable of automatic motion, constant in composition for any given race, and capable of synthesis only upon a pre-existing basis of their own kind.

The movement of chromatin along the linin thread from nucleolus to chromosome, and conversely, is due to progressive conversion of oxychromatin into chromatin, granule by granule. The excretion of chromatin which seems to take place in some cases might be merely extrusion of unnecessary, duplicate 'molecules'. When such extrusion is chemical the residue is oxy-chromatin. 


\section{Achromatic substances.}

Loosely divided into 'oxy-chromatin' and 'linin'. Oxy-chromatin is closely related to chromatin, but its synthesis from, or by, the linin can take place without the pre-existence of the 'molecular basis' (of chromatin) necessary for the formation of chromatin.

The linin is of simpler composition, but very unstable ; in consequence of this instability it has the power of movement.

There cannot well be differentiation of the oxy-chromatin granules, so that we may regard the dilated linin of a plasmosome as the reservoir in which the chromatin molecules rest. Their emergence from this retreat is the sign for their segregation or duplication.

Linin can pass back into the cytoplasm, as exemplified in the fading of inter-chromosome spindle fibres after division. It can also be reconstructed from the cytoplasm, as exemplified in the increased size of the synaptic mother-cell. It is closely related to cytoplasmic fibrillae, and may even be chemically identical with them, but it is morphologically distinct and discontinuous from them; the increase in bulk of either is probably due to direct synthesis from simpler, or even non-living, constituents of the cytoplasm.

It is worthy of note that the regularity of distribution of achromatic substance is far greater in the reduction division than in the vegetative divisions. In the latter, a large plasmosome may be very unequally divided.

It should be noted that the broken spindle fibres contain no oxychromatin granules, so that the latter are very evenly halved in the reduction division.

The behaviour of the thread-rings in fertilization has yet to be investigated. If the rings do not unite immediately-as seems probable-it will be of interest to determine the stage at which this happens, and to ascertain what takes place in synapsis.

The writer is inclined to regard the spireme stage, after the plasmosome has disappeared, as being the typical form of the nucleus. From this stage it departs towards the resting nucleus with chromatin aggregated in the plasmosome, or towards the differentiated chromosomes of the dividing nucleus. Any stage other than the close spireme might thus be regarded as an adaptation to some special requirement of the cell. The various chromosomes are likely to have definite places in this spireme, and to retain those places at each successive division; such geographical localization is not, however, an inevitable outcome of the present hypothesis. In those cases of vegetative division where the plasmosome is slung in the centre of the thread-ring by linin bridles, we see that complete breaking of the anastomoses of the reticulum is by no means necessary for regular division. In this way the spireme may have been phylogenetically derived from 
a plate, or even from a granule of motile linin, in which the chromatin was embedded.

My thanks are due to Mr. R. P. Gregory for his critical assistance and advice, and to the Khedivial Agricultural Society for the purchase of the $3 \mathrm{~mm}$. Zeiss apochromatic.

\section{REFERENCE.}

Cannon, W. A.: Spermatogenesis in Hybrid Cotton. Bull. Torrey Bot. Club, I900, p. 16r.

The only other paper concerned with cotton cytology. The observations agree with the writer's except in three points.

I. I have not noticed the 'filar plasm' in the peripheral cytoplasm, nor seen any spindle structures proper in this region.

2. The chromosomes in the Egyptian plant appear to be twenty in number, not twenty-eight.

3. The formation of chromosomes is not by mechanical condensation of loops. Cannon appears to have fallen into exactly the same error which I made in the first observations on the reduction divisions; I carefully prepared drawings of the loops of the thread-rings under the impression that they were chromosomes which were getting ready to shrink and thicken into the usual ' $U$ ' form, and it was not until I tried to follow out this shrinking-and also found mature chromosomes side by side with themthat I began to look for another explanation for these loops.

It is of interest to note that he recorded the conspicuous linin structures, and attributed the formation of part of the spindle to them, although without description or reasons. He also comments on the one-sided arrangement of the chromosomes in prophase.

The irregular divisions which he describes can be found in all cottonplants if very late flowers or very early ones on rattoons are taken; they are not necessarily due to hybrid constitution, and might very well have been provoked by the greenhouse culture he employed.

I might add that this work was in its present stage before I saw Cannon's paper for the first time.

\section{DESCRIPTION OF PLATE LIV.}

Illustrating Mr. Balls's article on the Mechanism of Nuclear Division.

The drawings were made with the Zeiss $3 \mathrm{~mm}$. apochromatic (excepting Figs. I and 2) and camera lucida, in blue light.

Figs. I, 2, 3, 4, and 7 are republished from the Year Book of the Khedivial Agricultural Society, 1905 .

Fig. I. Mature microspore mother-cell, not yet passed into synapsis, although the anther wall with its aborting tapetum and parietals shows it to be much older than Fig. 2, which is taken from 
another plant. Fixation good. $\quad \times 700$. ep., epidermis; $p^{1}, p^{2}$, parietals; m.c.n., microspore mother-cell nucleus; tap., tapetum.

Fig. 2. Synapsis. Younger anther, parietals and tapetum unaltered, but mother-cell nucleus already in synapsis. $\times 45^{\circ}$.

Fig. 3. Portion of spireme and nucleolus of synapsis, slightly later. Nucleolus scarcely shrunken, thread definitely split, chromatic areas fairly evenly spaced, and bisected. $\times$ I, roo.

Fig. 4. Very late spireme, showing two fully differentiated chromosomes, each of four units, split thread uniting them; nucleolus nearly gone, but still continuous with thread. $\times \mathrm{I}, \mathrm{IoO}$.

Fig. 5. The cluster of chromosomes at one side of the mother-cell nucleus, in prophase of first division. The halves of the spireme thread are conspicuous objects. The chromosome on the extreme left was seen clearly to be connected on either side to the 'thread-rings', by means of short fibres. $\times 900$.

Fig. 6. Late prophase of same division. Spindle fibres connecting chromosomes to threadrings, but not yet drawn taut in all cases. $\times \mathrm{J}, 300$.

Fig. 7. Metaphase of first division, separation of chromosomes commencing. Section slightly oblique to spindle, showing insertion of bunched spindle fibres in thread-rings at pole. $\quad \times 1,100$.

Fig. 8. The same, in another cell, showing spindle fibres below which have not yet been drawn up into the polar group. Semi-diagrammatic. $\times$ I, 500 about.

Fig. 9. One of the first pair of daughter-nuclei in prophase of second division. The arrow points to the other daughter-nucleus. Note that the loops of the thread-ring are double, approximately superposed (indicating origin by splitting) and unbroken on the side of the arrow. They can be followed throughout their length except on the polar side, where a portion is hidden by the chromosomes. $\times$ I,000. (Spindle fibres omitted.)

Fig. 10. Later prophase of same, showing rings very clearly. Semi-diagrammatic. $\times 1,500$.

Figs. II, I2, and I3. Division of vegetative cells in root-tip.

Fig. II. Polar view of prophase. Nucleolus stellate, slung by bridles of linin to one of the thread-rings. Peripheral chromosomes, connected to both rings by incipient spindle fibres. $\quad \times 1,500$.

Fig. I 2. Side view of spindle in metaphase, showing rings at either end, with spindle fibres ending upon them. $\times$ I, 100 .

Fig. I3. A single thread-ring in metaphase, showing the plasmosome in this case as a simple dilatation of the ring. $\times \mathrm{I}, 500$. 

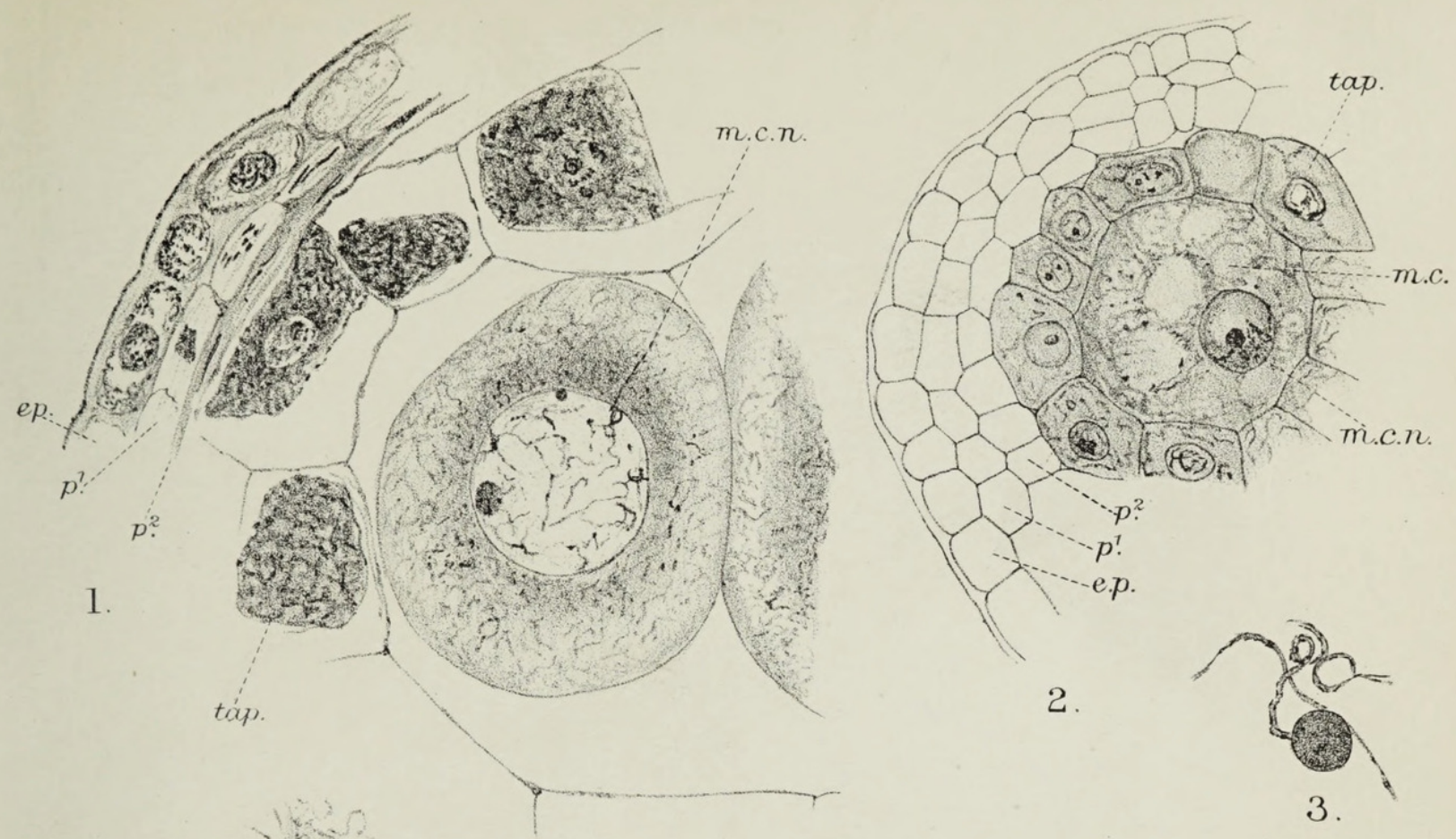

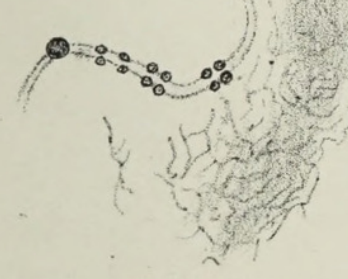

4.

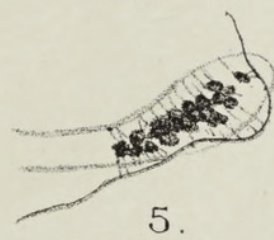

5.

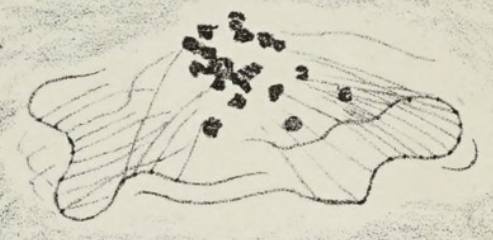

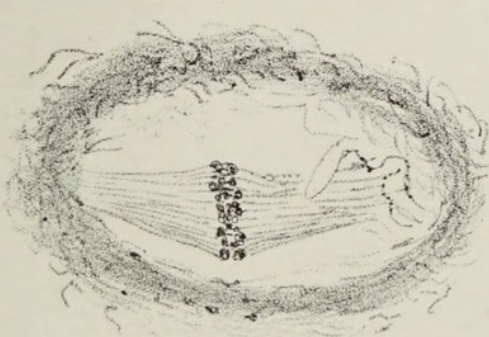

7

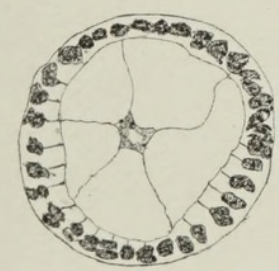

11.

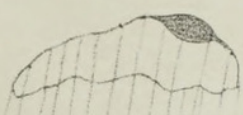

13.

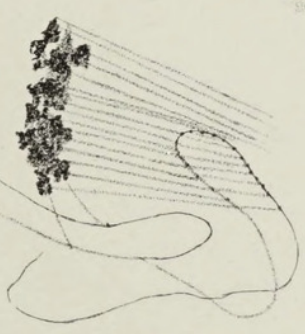

8

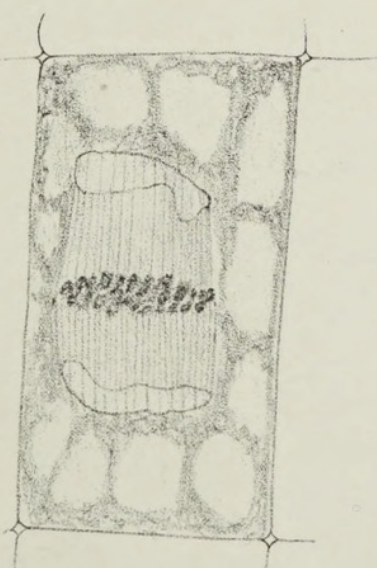

12
6
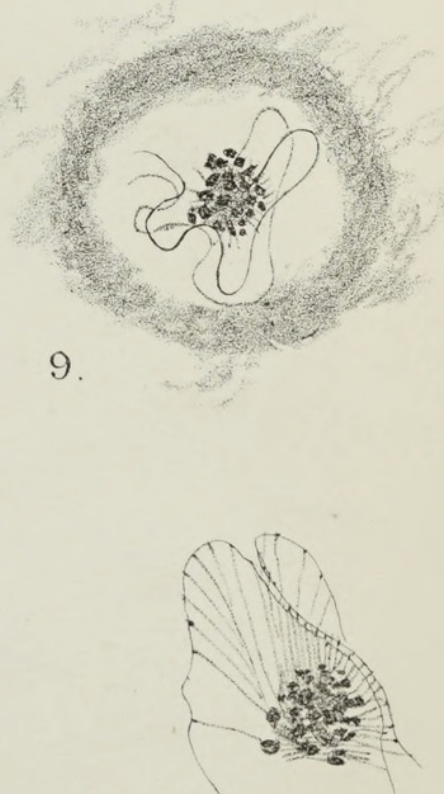

10. 


\section{$2 \mathrm{BHL}$ Biodiversity Heritage Library}

Balls, W. Laurence. 1910. "The mechanism of nuclear division." Annals of botany 24, 653-665. https://doi.org/10.1093/oxfordjournals.aob.a089296.

View This Item Online: https://www.biodiversitylibrary.org/item/262605

DOI: https://doi.org/10.1093/oxfordjournals.aob.a089296

Permalink: https://www.biodiversitylibrary.org/partpdf/319804

\section{Holding Institution}

New York Botanical Garden, LuEsther T. Mertz Library

\section{Sponsored by}

BHL-SIL-FEDLINK

\section{Copyright \& Reuse}

Copyright Status: Public domain. The BHL considers that this work is no longer under copyright protection.

This document was created from content at the Biodiversity Heritage Library, the world's largest open access digital library for biodiversity literature and archives. Visit BHL at https://www.biodiversitylibrary.org. 